\title{
Prediction of the elution profiles of proteins in mixed salt systems in hydrophobic interaction chromatography
}

\author{
Nadia Galeotti, Eva Hackemann, Fabian Jirasek* ${ }^{*}$ Hans Hasse \\ Laboratory of Engineering Thermodynamics (LTD), University of Kaiserslautern, 67663 \\ Kaiserslautern, Germany
}

\begin{abstract}
Hydrophobic interaction chromatography (HIC) is often used for purifying proteins. A mathematical model to describe the complex effects of salts on the adsorption equilibria in HIC has recently been introduced by our group. It describes not only the influence of single salts, but also salt mixtures, in which cooperative effects may occur. The influence of the salts is thereby modeled with a Taylor series expansion in the individual ion molarities. In the present study, the model of the adsorption equilibrium is coupled with a lumped kinetic model of the adsorption kinetics to obtain a model of the elution of proteins in HIC adsorption columns. The column model is tested using experimental data on the adsorption of bovine serum albumin (BSA) and lysozyme (LYS) on the mildly hydrophobic resin Toyopearl PPG-600M at pH 7. The studied salts are ammonium chloride, sodium chloride, ammonium sulfate, and sodium sulfate as well as binary and ternary mixtures of them. The parameters of the lumped kinetic model are proteinspecific and were fitted to the elution profiles of the single proteins in presence of single salts. The model was then used to predict the elution profiles of BSA and
\end{abstract}

\footnotetext{
${ }^{*}$ Corresponding author

Email address: fabian.jirasek@mv.uni-kl.de (Fabian Jirasek)
} 
LYS solutions containing both proteins, for single salts as well as for binary and ternary salt mixtures. Both isocratic and gradient elution were studied. Furthermore, the model was applied to identify the optimal overall ionic strength for the separation of the two proteins by isocratic elution and the optimal linear gradient of the salt concentration in a multicriteria approach where the conflicting goals are high separation yield and low elution volume.

Keywords: proteins, hydrophobic interaction chromatography, mixed electrolytes, conceptual process design, optimization

\section{Introduction}

Hydrophobic interaction chromatography (HIC) is an attractive method for the separation and purification of biological macromolecules [1-3]. In HIC, salts are used for controlling the solvent properties and the affinity of the target components to the adsorbent. Typically, single salts are utilized for this purpose and the influence of single salts on HIC is well studied [4-12]. Several thermodynamic models have been proposed to describe the influence of single salts on protein adsorption on HIC materials [10, 13-15]. In the last years, it has been shown that salt mixtures can lead to synergetic effects in HIC and consequently to a higher loading than the one that would be expected from interpolating the results of single salts [16-21]. Despite some attempts to describe the synergetic effects of salt mixtures on HIC [8], these effects are still only partly understood. Recently, our group has developed a mathematical model that is able to describe the influence of mixed salts on protein adsorption in HIC [18-20,22]. The model is based on a Taylor series expansion in the molarities of the individual ions. It is therefore called TAYSI model here (Taylor series single ions). It has been shown that the 
TAYSI model is able to describe the influence of mixed salts composed of up to four different salts on the loading of the adsorbent [18]. The information needed to parametrize this model for a certain protein-adsorbent system at a certain $\mathrm{pH}$ and a certain value of temperature is an adsorption isotherm for each single salt, plus, at least one additional adsorption isotherm for binary salt systems if cooperative salt effects are present [22]. The amount of information required for the training of the TAYSI model is low compared to its range of applicability. Once parametrized, the model is able to predict adsorption isotherms for any mixture of the salts that were included in the training set $[18-20,22]$ and for any ionic strength [19].

Predicting the elution behavior of proteins in HIC is particularly attractive for conceptual process design. The objective of this paper is to provide a simple, yet reliable, model for that purpose. It shall be based on the TAYSI model of the adsorption isotherms, yield predictions of the protein elution profiles, and thereby support the conceptual design of protein purification by HIC. Hence, we do not aim at a highly accurate prediction of elution profiles but rather want to develop a tool that enables comparing the influence of different salts on the separation and devising suitable strategies for choosing the salt gradients.

Most models of chromatographic separation that have been described in the literature combine an equilibrium adsorption isotherm model with models for the column fluid dynamics and the adsorption kinetics. A review on such models has recently been given by Guiochon et al. [23].

In this work, the TAYSI model [22] is used as equilibrium adsorption isotherm model and combined with a lumped kinetic model. For testing the model, chromatographic separations were studied for systems, for which adsorption isotherms 
were available from previous works $[19,20]$. The chromatographic experiments were carried out in the present study. The chromatographic separation that was investigated is that of the two proteins bovine serum albumin (BSA) and lysozyme (LYS) on the mildly hydrophobic resin Toyopearl PPG-600M. The parameters of the TAYSI model for BSA were taken from a previous work [22], while the parameters for LYS were refitted using data from a previous work [19] that were closer to the conditions relevant for the chromatographic separations of the present study. The parameters of the column model were obtained from fitting experimental elution profiles of single proteins.

Predictions of elution profiles of protein solutions containing both BSA and LYS are compared to experimental data both for isocratic and gradient elution. Moreover, the model was applied for optimizing the separation. Two conflicting goals were considered: the separation yield should be maximized and at the same time, the elution volume should be minimized. An isocratic and a gradient elution were identified that give a good compromise between the goals.

\section{Materials and methods}

\subsection{Materials}

BSA $(M \approx 66.4 \mathrm{kDa})$ with a purity of $98.5 \%$ and LYS $(M \approx 14.3 \mathrm{kDa})$ with a purity over $90 \%$ were obtained from Sigma-Aldrich. The salts used for the buffer preparation, namely monosodium phosphate dihydrate $\left(\mathrm{NaH}_{2} \mathrm{PO}_{4} \cdot 2 \mathrm{H}_{2} \mathrm{O}\right)$, disodium phosphate dihydrate $\left(\mathrm{Na}_{2} \mathrm{HPO}_{4} \cdot 2 \mathrm{H}_{2} \mathrm{O}\right)$, ammonium chloride $\left(\mathrm{NH}_{4} \mathrm{Cl}\right)$, sodium chloride $(\mathrm{NaCl})$, ammonium sulfate $\left(\left(\mathrm{NH}_{4}\right)_{2} \mathrm{SO}_{4}\right)$, and sodium sulfate $\left(\mathrm{Na}_{2} \mathrm{SO}_{4}\right)$ were of analytical grade and obtained from Carl Roth. Ultrapure water was produced in a Milli-Q system from Merck Millipore. The chromatographic column 
used for the measurements of elution profiles is an OPUS ${ }^{\circledR}$ MiniChrom column from Repligen with a volume of $10 \mathrm{~mL}$, a cross sectional area $A=1 \mathrm{~cm}^{2}$ and a packed bed height of $100 \mathrm{~mm}$. The column was obtained from Repligen prepacked with the hydrophobic resin Toyopearl PPG-600M from Tosoh Bioscience.

\subsection{Measurement of elution profiles}

The equilibration buffer used for the experiments is a $25 \mathrm{mM}$ sodium phosphate buffer with $\mathrm{pH}$ 7. The elution buffer consists of the equilibration buffer with the addition of extra salts in order to establish the desired conditions for the experiments. The added salts are $\mathrm{NH}_{4} \mathrm{Cl}, \mathrm{NaCl},\left(\mathrm{NH}_{4}\right)_{2} \mathrm{SO}_{4}$, and $\mathrm{Na}_{2} \mathrm{SO}_{4}$. Both, single salts as well as binary and ternary salt mixtures, were studied. The overall ionic strength of the elution buffer was $I=1 \mathrm{M}, 1.5 \mathrm{M}$, or $2 \mathrm{M}$, depending on the experiment. The $\mathrm{pH}$ value in the buffers was measured with a Metrohm $780 \mathrm{pH}$ meter and adjusted with $\mathrm{NaOH}$ or $\mathrm{H}_{3} \mathrm{PO}_{4}$ after adding the salts. Protein solutions were prepared by adding a known amount of the protein to a known volume of the elution buffer. The salts and the proteins were added gravimetrically with the precision balance AG 204 from Mettler Toledo having a resolution of $0.0001 \mathrm{~g}$. Isocratic and gradient elution experiments were carried out on an Äkta Purifier 100 UPC System from GE Healthcare equipped with a single-wavelength UV detector and a conductivity and $\mathrm{pH}$ combi-monitor and controlled with the UNICORN 5.2 system. The absorbance at $280 \mathrm{~nm}$ is used as protein signal and the salt concentration in the buffer is monitored using the signal of the conductivity detector. All the experiments were performed at room temperature $\left(25 \pm 2{ }^{\circ} \mathrm{C}\right)$ and $\mathrm{pH}$ 7. The flow rate was $1.0 \mathrm{ml} \mathrm{min}^{-1}$ and the injection volume was 0.5 or $1.0 \mathrm{ml}$.

The column was equilibrated before injecting the protein solution with the elution 
buffer until the monitored conductivity was stable for at least 5 minutes. Then, the protein solution was injected manually with a syringe. The salt concentration in the elution buffer was either constant throughout the experiment (isocratic elution) or was linearly decreased (gradient elution). The linear gradient was achieved by mixing the elution buffer with the equilibration buffer using two modules of the same pump P-900. After the end of the experiment, the column was first regenerated with the equilibration buffer and then either re-equilibrated with the elution buffer of the next experiment or flushed with ultrapure water and a $20 \mathrm{wt} . \%$ ethanol solution for storage.

Before starting the experiments, the porosity of the column was characterized experimentally as described in the Supplementary Information. The total volume of the column $V$ is given by the sum of three contributions:

$$
V=V_{\text {void }}+V_{\text {pore }}+V_{\text {rest }}
$$

where $V_{\text {void }}$ is the empty space between the adsorbent particles, $V_{\text {pore }}$ is the volume of the pores in the particles, and $V_{\text {rest }}$ is the volume of the solid phase of the adsorbent particles (excluding the pores). The total volume of the adsorbent particles is $V_{\text {pore }}+V_{\text {rest }}$. The external porosity $\varepsilon^{*}$ is defined as:

$$
\varepsilon^{*}=\frac{V_{\text {void }}}{V}
$$

and the total porosity $\varepsilon^{* *}$ is defined as:

$$
\varepsilon^{* *}=\frac{V_{\text {void }}+V_{\text {pore }}}{V}
$$


The numbers found for these properties in the experiments described in the Supplementary Information are $\varepsilon^{*}=0.4$ and $\varepsilon^{* *}=0.95$.

\subsection{Adsorption equilibria}

The equilibrium adsorption isotherms used in the present work are predicted using the TAYSI model [22], which describes the influence of the molarities of the single ions in the solvent on the loading of the adsorbent $q_{p}$ with a protein $p$ :

$$
\ln \frac{q_{p}\left(c_{p}\right)}{\mathrm{mM}}=k_{0}+\sum_{i} k_{i}\left(c_{p}\right) \frac{c_{i}}{c_{0}}+\frac{1}{2} \sum_{i} \sum_{j} k_{i j}\left(c_{p}\right) \frac{c_{i}}{c_{0}} \frac{c_{j}}{c_{0}}
$$

where $c_{p}$ is the molarity of the protein $p$ in the liquid phase, $c_{i}$ and $c_{j}$ are the molarities of the single ions $i$ and $j$, respectively, and $k_{0}, k_{i}$, and $k_{i j}$ are the model parameters. To obtain dimensionless parameters, $c_{0}=1000 \mathrm{mM}$ is introduced. The loading $q_{p}$ refers to the total volume of the adsorbent, i.e. to the sum $V_{\text {pore }}+$ $V_{\text {rest }}$. The sum over $i$ and $j$ covers all ions that are present in the solution. $k_{0}$ is the number of $\ln q_{p}\left(c_{p}\right)$ if no salt is present in the solution. That number is small here and arbitrarily set to - 6.91 [22]. The correlation for the dependence of $k_{i}$ and $k_{i j}$ on $c_{p}$ is:

$$
k=a_{1} \cdot \frac{\left(a_{3} \cdot c_{p}\right)^{a_{2}}}{1+\left(a_{3} \cdot c_{p}\right)^{a_{2}}}
$$

where $k$ is either $k_{i}$ or $k_{i j}$.

This correlation has the same form as the Langmuir-Freundlich or Sips isotherm [24, 25]. It is simple, but very flexible and enables accurate correlations of the results for $k_{i}\left(c_{p}\right)$ and $k_{i j}\left(c_{p}\right)$. This equation is used only as convenient algebraic expression without implying any physical significance in this context, notably for the parameters $a_{1}, a_{2}$, and $a_{3}$. This is in contrast to the parameters $k_{i}$ and $k_{i j}$ in Eq. 4. E.g. the $k_{i}\left(i\right.$ n.e. zero) describes the effect of the single ion $i$ on the loading $q_{p}$. If 
$k_{i}>0$ the ion $i$ leads to salting-out, if $k_{i}<0$ it leads to salting-in.

The HIC material, the proteins, and the salts in Ref. [22] were the same as those in the present study. The parameters $a_{1}, a_{2}$, and $a_{3}$ for BSA were taken directly from Ref. [22]. The numbers for $\mathrm{pH} 7$ are used, which is the $\mathrm{pH}$ value at which the experiments from the present work were carried out. For LYS, the parameters $a_{1}$, $a_{2}$, and $a_{3}$ that are reported in Ref. [22] were determined from a fit to data for an overall ionic strength of $2.7 \mathrm{M}$ that is substantially higher than the ionic strengths used in the present work. As Ref. [19] also contains data at lower ionic strengths, it was decided to refit the parameters $a_{1}, a_{2}$, and $a_{3}$ to these data. The differences between the results from both fits are not large, but we wanted to use the best available correlation of the equilibrium adsorption isotherms also for LYS.

The parameters $a_{1}, a_{2}$, and $a_{3}$ for both proteins BSA and LYS used in the present work are reported in Table 1. Figure 1 shows the results for $k_{i}$ and $k_{i j}$ as a function of $c_{p}$ for the two proteins.

Table 1: Parameters describing the dependence of model parameters $k_{i}$ and $k_{i j}$ on the solute concentration $c_{p}$ calculated by Eq. 5 for the adsorption of BSA [22] and LYS on Toyopearl PPG-600M at $25^{\circ} \mathrm{C}$ and $\mathrm{pH} 7$.

\begin{tabular}{|c|c|c|c|c|c|c|}
\hline & \multicolumn{3}{|l|}{ BSA } & \multicolumn{3}{|l|}{ LYS } \\
\hline & $a_{1}$ & $a_{2}$ & $a_{3}$ & $a_{1}$ & $a_{2}$ & $a_{3}$ \\
\hline$k_{\mathrm{Na}^{+}}$ & 0.85 & 0.50 & 402.56 & 3.0999 & 0.5473 & 115.0300 \\
\hline$k_{\mathrm{NH}_{4}^{+}}$ & 0.68 & 0.83 & 53.53 & 2.2293 & 0.8839 & 69.9800 \\
\hline$k_{\mathrm{Cl}^{-}}$ & 0.68 & 0.83 & 53.53 & 0.3209 & -0.1747 & 0.0002 \\
\hline$k_{\mathrm{SO}_{4}^{2-}}$ & 2.89 & 0.57 & 10171.84 & 2.2293 & 0.8839 & 69.9800 \\
\hline$k_{\mathrm{Cl}^{-}, \mathrm{SO}_{4}^{2-}}$ & -1.17 & -0.57 & 96.69 & 1.5663 & -0.4767 & 0.4074 \\
\hline
\end{tabular}




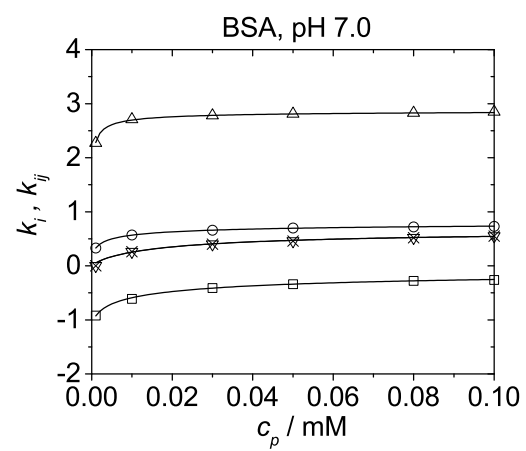

(a)

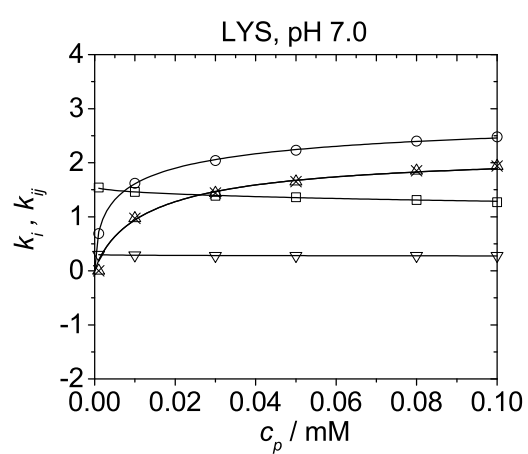

(b)

Figure 1: Parameters $k_{i}$ and $k_{i j}$ from Eq. 5 plotted over the protein concentration in the liquid phase at $\mathrm{pH} 7$ for BSA [22] (panel (a)) and for LYS [19] (panel (b)). The experimental values are shown as symbols $\left(\bigcirc \mathrm{Na}^{+}, \times \mathrm{NH}_{4}^{+}, \nabla \mathrm{Cl}^{-}, \triangle \mathrm{SO}_{4}^{2-}, \square \mathrm{Cl}^{-}, \mathrm{SO}_{4}^{2-}\right)$ and fits from Eq. 5 are shown as solid lines.

\subsection{Overview of the experimental program}

The elution profiles of the solutions containing single proteins were measured only for single salts, while the elution profiles of solutions containing both BSA and LYS were measured also for salt mixtures. The selection of the single salts and salt mixtures that were studied was based on a preliminary screening, as described in the following, using information of the adsorption equilibria that was obtained with the TAYSI model. The loading of the adsorbent at a protein concentration in the liquid phase of $0.01 \mathrm{mM}\left(q_{p}\left(c_{p}=0.01 \mathrm{mM}\right)\right)$ was calculated for BSA and LYS at a constant ionic strength at varying composition of the salt mixtures. In Figure 2, the logarithm of $q_{\mathrm{LYS}}\left(c_{\mathrm{LYS}}=0.01 \mathrm{mM}\right) / q_{\mathrm{BSA}}\left(c_{\mathrm{BSA}}=0.01 \mathrm{mM}\right)$ is plotted on the $z$ axis against the molarities of the ions $\mathrm{Na}^{+}$and $\mathrm{Cl}^{-}$on the $x$ and $y$ axes. 


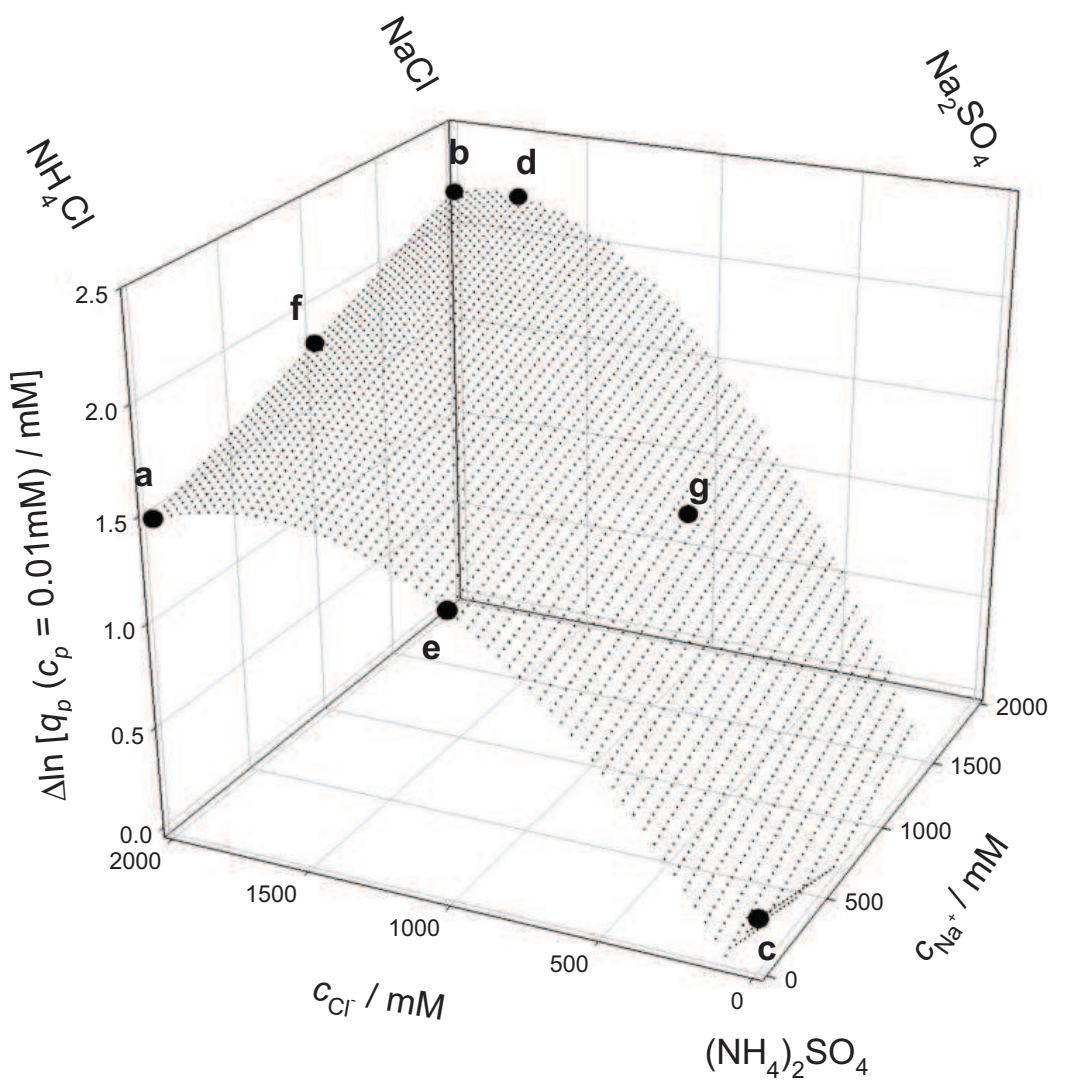

Figure 2: Difference between the loading of the adsorbent PPG-600M with LYS and BSA at a protein concentration in the solvent of $0.01 \mathrm{mM}, \mathrm{pH} 7, I=2 \mathrm{M}$, and $25^{\circ} \mathrm{C}$ as a function of the composition of the elution buffer. The elution buffers are composed of the four salts of which the names are given in the corners of the diagram. The composition is fully specified by the concentrations of the $\mathrm{Na}^{+}$and $\mathrm{Cl}^{-}$ions. The dots marked with letters show the composition of the elution buffers that were studied in the chromatographic experiments in the present work. $2 \mathrm{M}$ $\mathrm{NH}_{4} \mathrm{Cl}$ (a), $2 \mathrm{M} \mathrm{NaCl}$ (b), $0.67 \mathrm{M}\left(\mathrm{NH}_{4}\right)_{2} \mathrm{SO}_{4}$ (c), $1.7 \mathrm{M} \mathrm{NaCl}+0.1 \mathrm{M} \mathrm{Na}_{2} \mathrm{SO}_{4}$ (d), $1 \mathrm{M} \mathrm{NH}_{4} \mathrm{Cl}+0.33 \mathrm{M}\left(\mathrm{NH}_{4}\right)_{2} \mathrm{SO}_{4}(\mathrm{e}), 1 \mathrm{M} \mathrm{NaCl}+1 \mathrm{M} \mathrm{NH}_{4} \mathrm{Cl}$ (f), and $0.12 \mathrm{M}$ $\mathrm{NaCl}+0.44 \mathrm{M} \mathrm{Na}_{2} \mathrm{SO}_{4}+0.57 \mathrm{M} \mathrm{NH}_{4} \mathrm{Cl}(\mathrm{g})$.

The studied solutions contain only $\mathrm{Na}^{+}, \mathrm{NH}_{4}{ }^{+}, \mathrm{Cl}^{-}$, and $\mathrm{SO}_{4}{ }^{2-}$. As the ionic strength is constant and the electroneutrality condition holds, the composition of the salt mixture is fully specified by specifying only $\mathrm{Na}^{+}$and $\mathrm{Cl}^{-}$. It follows from 
this argument, that the single salts $\left(\mathrm{NH}_{4} \mathrm{Cl}, \mathrm{NaCl},\left(\mathrm{NH}_{4}\right)_{2} \mathrm{SO}_{4}\right.$, and $\left.\mathrm{Na}_{2} \mathrm{SO}_{4}\right)$ are found in the corners of the plot shown in Figure 2. For more information on such plots, see Refs. [18-20, 22]. The results reported in Figure 2 were obtained for $\mathrm{pH} 7$ and $I=2 \mathrm{M}$. At these conditions, the adsorption of LYS is stronger than that of BSA for all salt mixtures except those containing predominantly ammonium sulfate. The results shown in Figure 2 indicate that mixtures of sodium chloride and sodium sulfate with a strong excess of sodium chloride are particularly favorable for the separation of the two proteins.

In Figure 2, the salt mixtures used for the measurement of elution profiles in this work are marked. The measurements were realized for three single salts $(a, b, c)$, for three binary mixture $(d, e, f)$, one of which $(d)$ is the one with the highest value of $\ln \left(q_{\mathrm{LYS}}\left(c_{\mathrm{LYS}}=0.01 \mathrm{mM}\right) / q_{\mathrm{BSA}}\left(c_{\mathrm{BSA}}=0.01 \mathrm{mM}\right)\right)$, i.e. the most favorable salt mixture for the separation based on adsorption equilibrium data, and a ternary salt mixture $(\mathrm{g})$.

\subsection{Mathematical model of the chromatographic separation}

The model that is used in the present work for describing the retention of a protein $p$ in a chromatographic column is obtained by combining a differential mass balance equation (Eq. 6) with a lumped mass transfer kinetic equation (Eq. 7). The differential mass balance equation is:

$$
\frac{\partial c_{p}}{\partial t}+\frac{\left(1-\varepsilon_{p}^{*}\right)}{\varepsilon_{p}^{*}} \frac{\partial q_{p}}{\partial t}+v_{p} \frac{\partial c_{p}}{\partial z}=0 \quad p=\text { BSA, LYS }
$$

where $t$ is the time and $z$ is the column axial coordinate. $c_{p}(z, t)$ is the concentration of the protein $p$ in the liquid phase and $q_{p}(z, t)$ is the loading of the adsorbent with the protein $p$ per volume of the porous adsorbent. $v_{p}$ is the effective flow 
velocity of the protein $p$ and $\varepsilon_{p}^{*}$ is the external porosity (cf. Eq. 2) where it is assumed that $1-\varepsilon_{p}^{*}$ is the volume fraction of the column that takes part in the adsorption. The number for $\varepsilon_{p}^{*}$ is considered to be protein-specific here.

The lumped mass transfer kinetic equation is obtained from a linear driving force model [23]:

$$
\frac{\partial q_{p}}{\partial t}=k_{p}\left(c_{p}-c_{p}^{\mathrm{eq}}\left(q_{p}\right)\right) \quad p=\mathrm{BSA}, \mathrm{LYS}
$$

where $k_{p}$ is the protein-specific lumped mass transfer coefficient and $c_{p}^{\mathrm{eq}}\left(q_{p}\right)$ is the protein concentration in the liquid phase in equilibrium with a stationary phase loaded with $q_{p}$. The value of $c_{p}^{\mathrm{eq}}\left(q_{p}\right)$ is determined from the TAYSI model.

In this model, the protein concentration profile in the column is assumed to be unidimensional, i.e. radially homogeneous. The axial dispersion is neglected and it is assumed that the volumetric flow of the mobile phase through the column is constant and that the electrolytes are not adsorbed. Furthermore, it is assumed that proteins do not interact with each other. Following this assumption, Eqs. 6 and 7 can be solved for each protein separately. The elution profile is then obtained by plotting the total protein concentration at the exit of the column of length $\mathrm{L}$ $\left(\sum_{p} c_{p}(z=\mathrm{L}, t)\right)$ against the elution volume $V_{\text {elution }}$, i.e. the total volume of the mobile phase that has eluted from the column between $t=0$ and time $t$.

Models of this type have been used before in the literature [23, 26-30]. In the present work, $v_{p}, \varepsilon_{p}^{*}$, and $k_{p}$ are considered to be model parameters that depend on the protein $p$ but are otherwise state-independent. They were obtained from a fit to experimental data of the elution profiles of the single proteins BSA and LYS for single salts as described below in more detail. We acknowledge that these parameters have physical interpretations and discuss the results of the fits on this background. We have chosen this empirical approach, as the main goal of the 
present study was not to develop a detailed physical model of the adsorption process but rather a simple and robust one. The present model can be parametrized easily based on a limited amount of data and then be used for conceptual process design, where the main goal is to determine promising salts (including mixtures) and gradients for the separation.

The initial and boundary conditions to solve the partial differential equation (Eqs. 6 and 7) are set in accordance with the experimental procedure. As already explained in Chapter 2.2, the column is regenerated and equilibrated before injecting the protein solution, i.e. the initial protein concentration in the liquid phase and the initial loading of the adsorbent are zero in the whole column. It is assumed that the injection of the sample can be described as a rectangular pulse with protein concentration $c_{p}^{\text {in }}$ and time $t_{\text {pulse }}$ where $t_{\text {pulse }}$ is defined as:

$$
t_{\text {pulse }}=\frac{V_{\text {pulse }}}{\dot{V}}
$$

where $V_{\text {pulse }}$ is the volume of the protein solution that is injected and $\dot{V}$ the flow rate. The initial and boundary conditions are specified in Eqs. 9-11:

$$
\begin{array}{lll}
c_{p}(z, t=0)=0 \text { for } 0 \leq z \leq L & p=\mathrm{BSA}, \mathrm{LYS} \\
c_{p}(z=0, t)=c_{p}^{\text {in }} \text { for } 0<t \leq t_{\text {pulse }} & p=\mathrm{BSA}, \mathrm{LYS} \\
c_{p}(z=0, t)=0 \quad \text { for } t>t_{\text {pulse }} & p=\mathrm{BSA}, \mathrm{LYS}
\end{array}
$$

For the numerical solution, Eqs. 6 and 7 are discretized and the three differential quotients are replaced by finite difference quotients such that the time evolution 
of the system can be determined by simple forward integration:

$$
\begin{array}{ll}
\frac{\partial x}{\partial t}=\frac{x(z, t)-x(z, t-1)}{\Delta t} & x=c_{p}, q_{p} \\
\frac{\partial x}{\partial z}=\frac{x(z, t-1)-x(z-1, t-1)}{\Delta z} & x=c_{p}
\end{array}
$$

The resulting system of equations was solved using the MATLAB function fsolve in the code version R2017b. Calculations were done with $\Delta t=1 \mathrm{~s}$ and $\Delta z=1 \mathrm{~mm}$. The salt concentration in the column is decisive for the adsorption process and has to be known at all times $t$ and positions $z$ in the column. The considered salts are $s=\mathrm{NH}_{4} \mathrm{Cl}, \mathrm{NaCl},\left(\mathrm{NH}_{4}\right)_{2} \mathrm{SO}_{4}$, and $\mathrm{Na}_{2} \mathrm{SO}_{4}$. For the case of an isocratic elution, taking into consideration the assumption that the salt is not adsorbing and the fact that the column is equilibrated with the elution buffer before the injection of the protein solution, the salt concentration is constant at $c_{s}^{\text {in }}$ over time in the entire column:

$$
c_{s}(z, t)=c_{s}^{\text {in }} \quad \text { for } 0 \leq z \leq \mathrm{L} \text { and } t \geq 0
$$

For the gradient elution, the differential mass balance for the salt must be solved, taking into consideration that the salts do not adsorb:

$$
\frac{\partial c_{s}}{\partial t}+v_{s} \frac{\partial c_{s}}{\partial z}=0
$$

where $v_{s}$ is the effective flow velocity of the salt $s$.

The effective flow velocity of the salt $v_{s}$ is not treated as an adjustable parameter, as it is done with $v_{p}$. Rather, it is calculated from geometric arguments from 
experimental numbers for the volumetric flow rate $\dot{V}$, the column cross sectional area $A$, and the total porosity $\varepsilon^{* *}$, which yields: $v_{s}=0.176 \mathrm{~mm} \mathrm{~s}^{-1}$. This value is used for all calculations of the present work.

The initial condition to solve the partial differential equation for the salt (Eq. 15) describes the fact that the column is equilibrated with the elution buffer before the injection of the protein solution and the boundary conditions impose the linear decrease of the salt concentration from the initial concentration $c_{s}^{\text {in }}$ to the final concentration $c_{s}^{\text {out }}$ during the volume $V_{\text {gradient }}$. The linear decrease begins after the time $t_{\text {pulse. }}$ The initial and boundary conditions are:

$$
\begin{array}{ll}
c_{s}(z, t=0)=c_{s}^{\text {in }} & \text { for } 0 \leq z \leq L \\
c_{s}(z=0, t)=c_{s}^{\text {in }} & \text { for } t \leq t_{\text {pulse }} \\
c_{s}(z=0, t)=c_{s}(z=0, t-1)+y & \text { for } t>t_{\text {pulse }}
\end{array}
$$

with

$$
y=\frac{c_{s}^{\text {out }}-c_{s}^{\text {in }}}{V_{\text {gradient }}} \cdot \dot{V} \cdot \Delta t
$$

In this work, only linear gradients are investigated, but it is possible to model also step gradients or other kinds of gradients by simply changing the boundary conditions in Eqs. 17-19. 


\section{Results and discussion}

\subsection{Studies with single proteins and single salts - Parametrization of the model}

The protein-specific model parameters $v_{p}, \varepsilon_{p}^{*}$, and $k_{p}$ were determined from fits to results from isocratic experiments with the single proteins and single salts. It would in principle be sufficient to use only one experiment for each protein with an arbitrarily chosen salt to obtain these parameters. But we have decided to make experiments with all four salts for which adsorption isotherms were available, to be able to make comparisons. Only the combination LYS $+\mathrm{Na}_{2} \mathrm{SO}_{4}$ was excluded, as the description of the adsorption equilibrium for that system by the present parametrization of the TAYSI model was found to be weak. For completeness, the adsorption isotherms calculated using the TAYSI model for LYS and all single salt systems are reported in Supplementary Information.

The protein-specific parameters for BSA were fitted to the isocratic elution profiles of pure BSA with elution buffers with $I=2 \mathrm{M}$ containing one of the four salts $\mathrm{NH}_{4} \mathrm{Cl}, \mathrm{NaCl},\left(\mathrm{NH}_{4}\right)_{2} \mathrm{SO}_{4}$, and $\mathrm{Na}_{2} \mathrm{SO}_{4}$. The protein-specific parameters for LYS were fitted to the isocratic elution profiles of pure LYS with elution buffers with $I=2 \mathrm{M}$ containing one of the three salts $\mathrm{NH}_{4} \mathrm{Cl}, \mathrm{NaCl}$, and $\left(\mathrm{NH}_{4}\right)_{2} \mathrm{SO}_{4}$. Additionally, the isocratic elution profiles of pure LYS with $\mathrm{NaCl}$ were determined for $I=1.5$ and $1 \mathrm{M}$.

The protein-specific parameters for both proteins were determined from the fitting by a minimization of the sum of squared residues as described in the following objective function $O F$ :

$$
O F=\sum_{j=1}^{N}\left[c_{p}^{\exp }\left(L, t_{j}\right)-c_{p}^{\mathrm{calc}}\left(L, t_{j}\right)\right]^{2}
$$


where $j$ is the index of data points corresponding to time $t_{j}$ and $N$ is the number of data points. For the calculation of the sum of squared residues, it was first necessary to convert the experimental data from absorbance units to concentration in $\mathrm{mg} \mathrm{ml}^{-1}$. This was done as explained in the Supplementary Information. The minimization was realized using the Matlab function fmincon. The following bounds were applied in the fit: $0<\varepsilon_{p}^{*}<0.95$ and $0.18 \mathrm{~mm} \mathrm{~s}^{-1}<v_{p}<0.42 \mathrm{~mm} \mathrm{~s}^{-1}$. The upper bound for $\varepsilon_{p}^{*}$ is the experimental number for the total porosity $\varepsilon^{* *}$, which should not be exceeded. The upper bound for $v_{p}$ is calculated from the experimental number for the external porosity $\varepsilon^{*}$, which gives an upper limit for the velocity. In the same way, the experimental number for the total porosity $\varepsilon^{* *}$ determines the lower bound for the velocity $v_{p}$. The obtained parameters are reported in Table 2 . The model results for BSA and LYS are compared to the experimental data in Figures 3 and 4, where elution profiles are shown.

Table 2: Protein-specific parameters of the model for the chromatographic separation presented in Chapter 2.5 (Eqs. 6 and 7).

\begin{tabular}{llll}
\hline$p$ & $\varepsilon_{p}^{*}$ & $v_{p} / \mathrm{mm} \mathrm{s}^{-1}$ & $k_{p} / \mathrm{s}^{-1}$ \\
\hline BSA & 0.95 & 0.186 & 0.081 \\
LYS & 0.23 & 0.419 & 0.347 \\
\hline
\end{tabular}




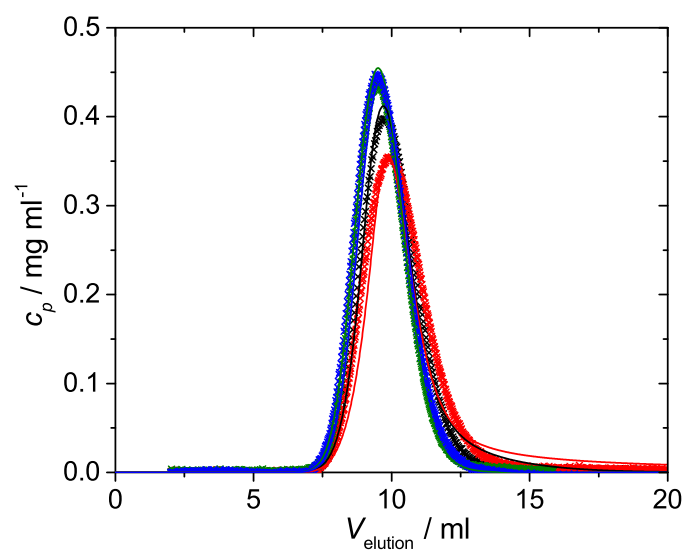

Figure 3: Isocratic elution profiles of $\mathrm{BSA}$ at $25^{\circ} \mathrm{C}, \mathrm{pH} 7$, and $I=2 \mathrm{M}$ using the adsorbent Toyopearl PPG-600M. $c_{p}^{\text {in }}=1 \mathrm{mg} \mathrm{ml}^{-1}$ and $V^{\text {in }}=1 \mathrm{ml}$. The crosses are experimental values from this work and lines results from the model. Data for different salts in the elution buffer: $\mathrm{NH}_{4} \mathrm{Cl}$ (green), $\mathrm{NaCl}$ (blue), $\left(\mathrm{NH}_{4}\right)_{2} \mathrm{SO}_{4}$ (black), and $\mathrm{Na}_{2} \mathrm{SO}_{4}$ (red).

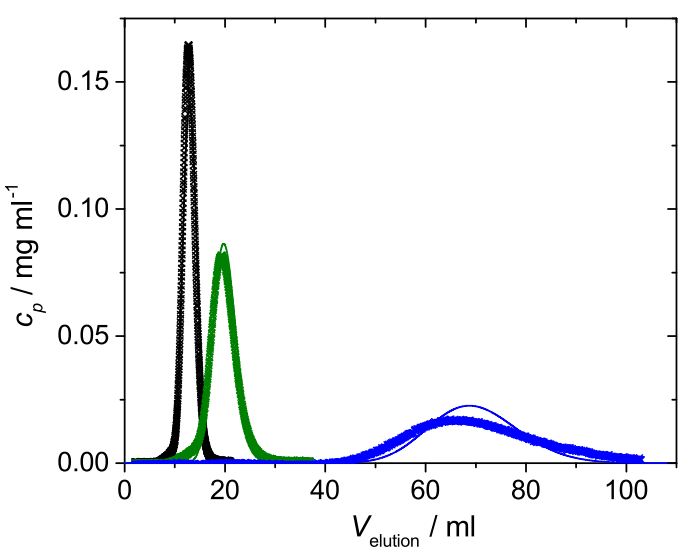

Figure 4: Isocratic elution profiles of LYS at $25^{\circ} \mathrm{C}, \mathrm{pH} 7$, and $I=2 \mathrm{M}$ using the adsorbent Toyopearl PPG-600M. $c_{p}^{\text {in }}=1 \mathrm{mg} \mathrm{ml}^{-1}$ and $V^{\text {in }}=0.5 \mathrm{ml}$. The crosses are experimental values from this work and lines are results from the model. Data for different salts in the elution buffer: $\mathrm{NH}_{4} \mathrm{Cl}$ (green), $\mathrm{NaCl}$ (blue), and $\left(\mathrm{NH}_{4}\right)_{2} \mathrm{SO}_{4}$ (black). 
The adsorption of BSA is weak at the studied conditions and the elution profiles for all salts are similar and described well by the model (cf. Figure 3). Also the results for LYS are described well (cf. Figure 4). Here, the salts have a strong influence on the elution profiles. The biggest deviation between the experimental data and the model is found for $\mathrm{NaCl}$, for which the results of the model show a higher retention time and a less broad peak, which is not astonishing as the axial dispersion was neglected in the model. The influence of the salt concentration on the elution profile, which was studied only for $\mathrm{NaCl}$, is shown in Figure 5.

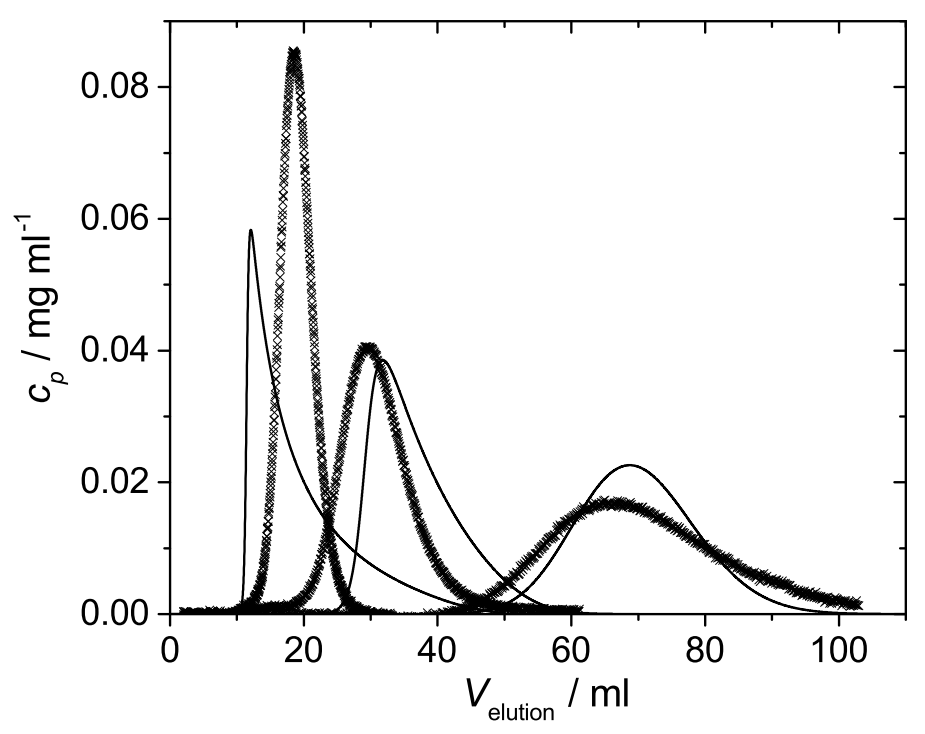

Figure 5: Isocratic elution profiles of LYS at $25^{\circ} \mathrm{C}$ and $\mathrm{pH} 7$ with the salt $\mathrm{NaCl}$ using the adsorbent Toyopearl PPG-600M. $c_{p}^{\text {in }}=1 \mathrm{mg} \mathrm{ml}^{-1}$ and $V^{\text {in }}=0.5 \mathrm{ml}$. The crosses are experimental values from the present work and lines are results from the model. $I=1 \mathrm{M}$ for the the peak on the left, $I=1.5 \mathrm{M}$ for the peak in the middle, and $I=2 \mathrm{M}$ for the peak on the right.

The simple model describes the trends correctly, but there are significant devia- 
tions regarding the form of the peaks (no tailing is observed in the experiments) and the retention time. For a conceptual process design, such deviations may still be acceptable. The highest deviation is observed for the lowest overall ionic strength of $1 \mathrm{M}$ which is not astonishing as the parameters of the TAYSI model were obtained from a fit to experimental data of adsorption isotherms at an overall ionic strength of $2.4 \mathrm{M}$ and the lumped kinetic model for the description of column dynamics has been trained mostly on experimental data at high ionic strength. The numbers for the model parameters (cf. Table 2) should not be over-interpreted, even though, in general, they lie in the range of the physical expectations. This is valid also for the values of $k_{p}$ which lie in the range of those reported by Creasy et al. [26]. The exception is in the value for $\varepsilon_{\mathrm{LYS}}^{*}$, which is below the experimental value for $\varepsilon^{*}$. In two cases, the numbers of the parameters are at or close to the bounds that were set from physical arguments $\left(\varepsilon_{\mathrm{BSA}}^{*}\right.$ and $\left.v_{\mathrm{LYS}}\right)$. 


\subsection{Prediction of isocratic elution profiles of BSA and LYS}

The comparison of the experimental data and the model predictions for the isocratic elution profiles for elution buffers containing single salts is shown in Figure 6.

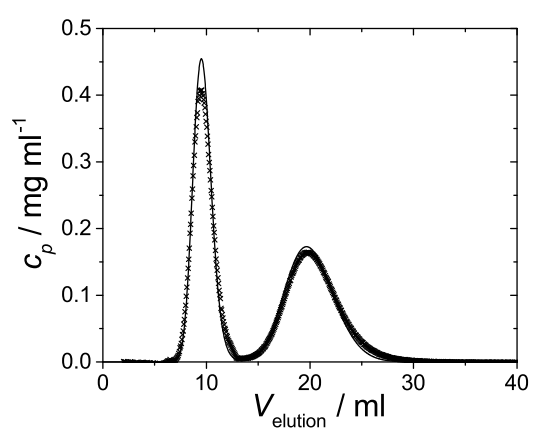

(a)

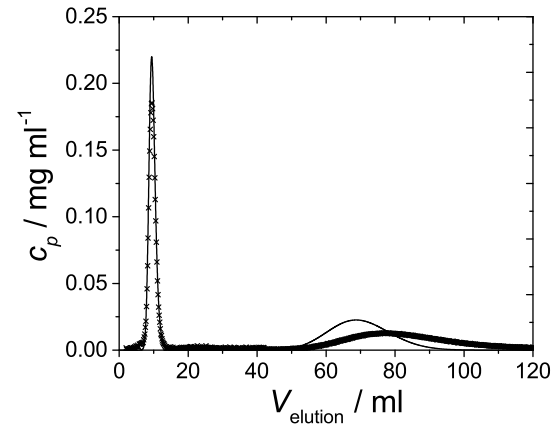

(b)

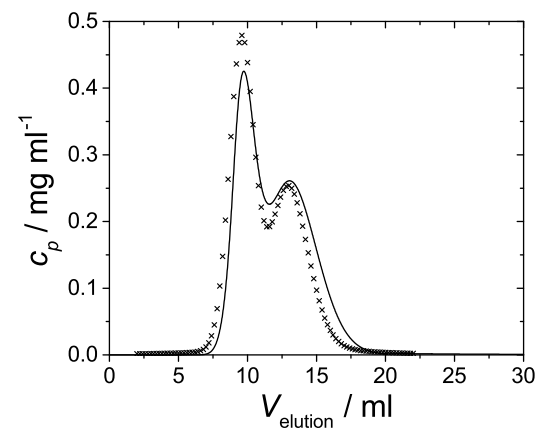

(c)

Figure 6: Isocratic elution profiles of protein solutions containing both BSA and LYS at $25^{\circ} \mathrm{C}, \mathrm{pH} 7$, and $I=2 \mathrm{M}$ using the adsorbent Toyopearl PPG-600M. The crosses are experimental values from this work and lines results from the model. Data for different salts in the elution buffer: $\mathrm{NH}_{4} \mathrm{Cl}$ (panel (a)), $\mathrm{NaCl}$ (panel (b)), and $\left(\mathrm{NH}_{4}\right)_{2} \mathrm{SO}_{4}$ (panel (c)). $c_{p}^{\text {in }}=1 \mathrm{mg} \mathrm{ml}^{-1}$ and $V^{\text {in }}=0.5 \mathrm{ml}$ for the elution profile with $\mathrm{NaCl}$ and $V^{\text {in }}=1 \mathrm{ml}$ for the elution profiles with $\mathrm{NH}_{4} \mathrm{Cl}$ and $\left(\mathrm{NH}_{4}\right)_{2} \mathrm{SO}_{4}$. In all three plots, the first peak represents BSA and the second LYS. 
In Figure 6, the letters of the panels (a-c) correspond to the letters in Figure 2 showing the composition of the elution buffers. The predictions of the model are in good agreement with the experimental data. This confirms that neglecting the competitive adsorption between different proteins in the model is a reasonable assumption here. At the investigated conditions, with a protein sample load of maximum $1 \mathrm{mg}$, the competitive adsorption obviously does not play a major role. The effect of the competitive adsorption is visible only for the elution profile measured with the single salt $\mathrm{NaCl}$. For the protein solution containing both proteins, the retention time for BSA remains unchanged compared to the retention time measured for the single protein, while the retention time for LYS slightly increases. For this reason, in Figure 6 panel (b), LYS is predicted to elute faster than in the experiments.

The comparison between experimental data and model predictions for isocratic elution profiles for which the elution buffer consists of salt mixtures is shown in Figure 7. 


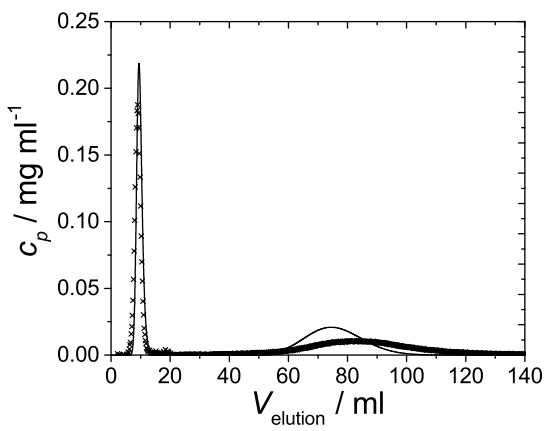

(d)

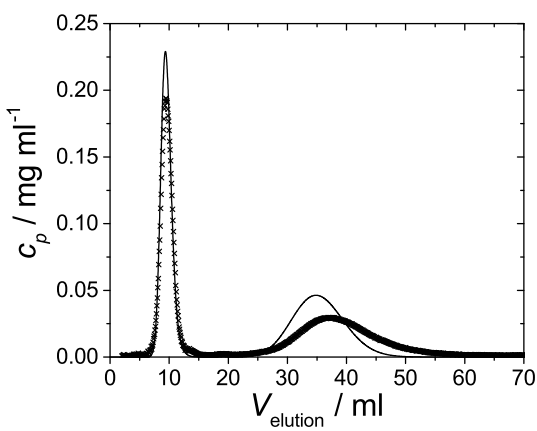

(f)

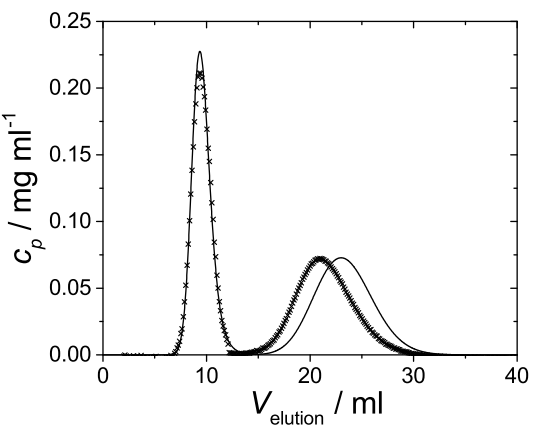

(e)

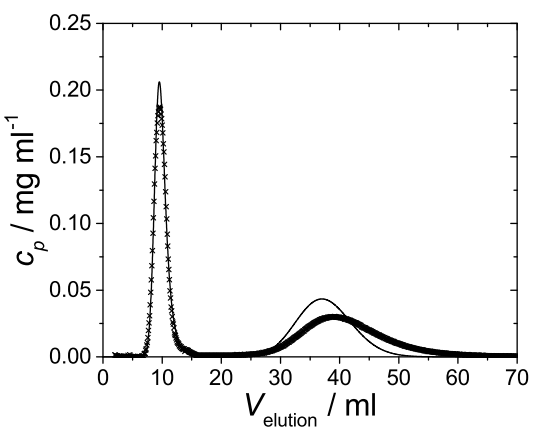

(g)

Figure 7: Isocratic elution profiles of protein solutions containing both BSA and LYS at $25^{\circ} \mathrm{C}$, pH 7, and $I=2 \mathrm{M}$ using the adsorbent Toyopearl PPG-600M. $c_{p}^{\text {in }}=1 \mathrm{mg} \mathrm{ml}^{-1}$ and $V^{\text {in }}=0.5 \mathrm{ml}$. The crosses are experimental values from this work and lines results from the model. Data for different salts in the elution buffer: $1.7 \mathrm{M} \mathrm{NaCl}+0.1 \mathrm{M} \mathrm{Na}_{2} \mathrm{SO}_{4}\left(\right.$ panel (d)), $1 \mathrm{M} \mathrm{NH}_{4} \mathrm{Cl}+0.33 \mathrm{M}\left(\mathrm{NH}_{4}\right)_{2} \mathrm{SO}_{4}$ (panel (e)), $1 \mathrm{M} \mathrm{NaCl}+1 \mathrm{M} \mathrm{NH}_{4} \mathrm{Cl}$ (panel (f)), $0.12 \mathrm{M} \mathrm{NaCl}+0.44 \mathrm{M} \mathrm{Na}_{2} \mathrm{SO}_{4}+0.57 \mathrm{M}$ $\mathrm{NH}_{4} \mathrm{Cl}$ (panel $(\mathrm{g})$ ). In all four plots, the first peak represents BSA and the second LYS.

Also here, the letters of the panels (d-g) correspond to the letters in Figure 2. Again a good agreement between experimental data and predictions of the model is found. The predictions of the elution profiles are not highly accurate, but they 
are sufficient for conceptual separation process design. Hence, the model was used for optimizations, on which we report in the following sections.

\subsection{Optimization of the separation of BSA and LYS}

As can be seen in panel (d) of Figure 7, an isocratic elution with an overall ionic strength of $I=2 \mathrm{M}$ and a elution buffer containing $1.7 \mathrm{M} \mathrm{NaCl}+0.1 \mathrm{M} \mathrm{Na}_{2} \mathrm{SO}_{4}$ gives, as expected, an excellent separation of the two proteins, but the elution volume necessary to complete the elution of both proteins is high (around $120 \mathrm{ml}$ ). Only this salt mixture is considered in the following optimization. The elution volume necessary to complete the elution $\left(V_{\text {elution }}^{\text {end }}\right)$ is defined in this work as the elution volume at which the LYS signal has fallen to $1 \%$ of its maximum value. The separation yield is defined as the ratio between the quantity of protein separated with a purity over $99.9 \%$ and the total quantity of protein to be separated. The elution volume necessary to complete the elution can be reduced by using an isocratic elution with a lower overall ionic strength or by gradient elution.

For the optimizations, the elution profiles of the same protein solution containing both proteins BSA an LYS were predicted for values of overall ionic strengths between $2 \mathrm{M}$ and $0.8 \mathrm{M}$. The predicted elution profiles are plotted in the $3 \mathrm{D}$ diagram in Figure 8 (panel (a)). The same results can be projected on a $2 \mathrm{D}$ diagram in form of a contour graph, which is shown in Figure 8 (panel (b)). 


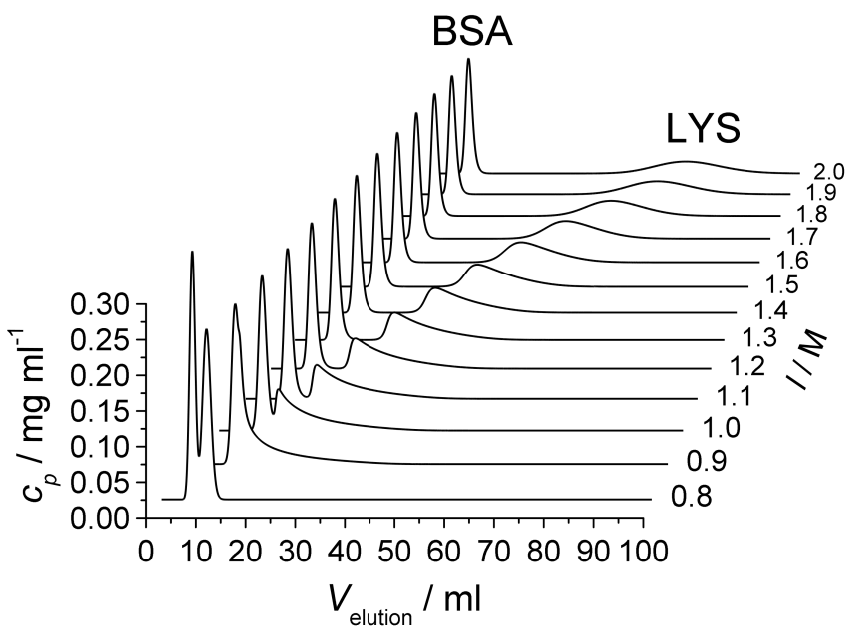

(a)

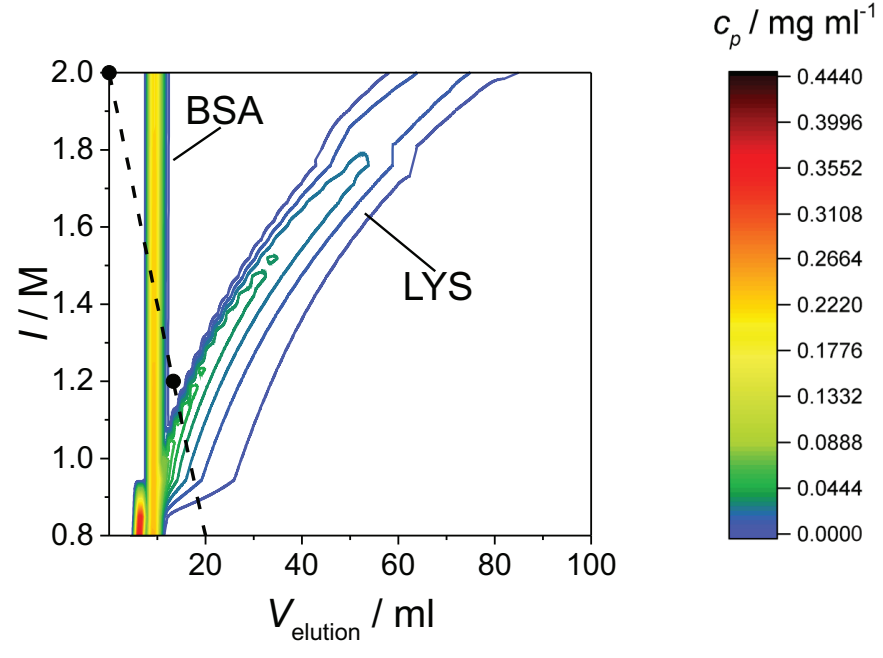

(b)

Figure 8: Predictions of the isocratic elution profiles of protein solutions containing both BSA and LYS at $25{ }^{\circ} \mathrm{C}$ and $\mathrm{pH} 7$ using the adsorbent Toyopearl PPG$600 \mathrm{M}$ and different values of the overall ionic strength, for an elution buffer containing $1.7 \mathrm{M} \mathrm{NaCl}+0.1 \mathrm{M} \mathrm{Na}_{2} \mathrm{SO}_{4} \cdot c_{p}^{\text {in }}=1 \mathrm{mg} \mathrm{ml}^{-1}$ for both proteins $p=\mathrm{BSA}$, LYS and $V^{\text {in }}=0.5 \mathrm{ml}$. Elution profiles (panel (a)) and contour graph (panel (b)). ...... - illustrates a simple way of choosing a linear gradient. 
High separation yields are found for overall ionic strengths higher than 1.2 M. For lower overall ionic strengths, the two peaks start to overlap and the separation yield gets worse. In Figure 9, the two objective functions, the elution volume necessary to complete the elution ( $V_{\text {elution }}^{\text {end }}$ ) and the separation yield of the protein LYS ( $\left.\mathrm{Y}_{\mathrm{LYS}}\right)$, are plotted in form of a Pareto front.

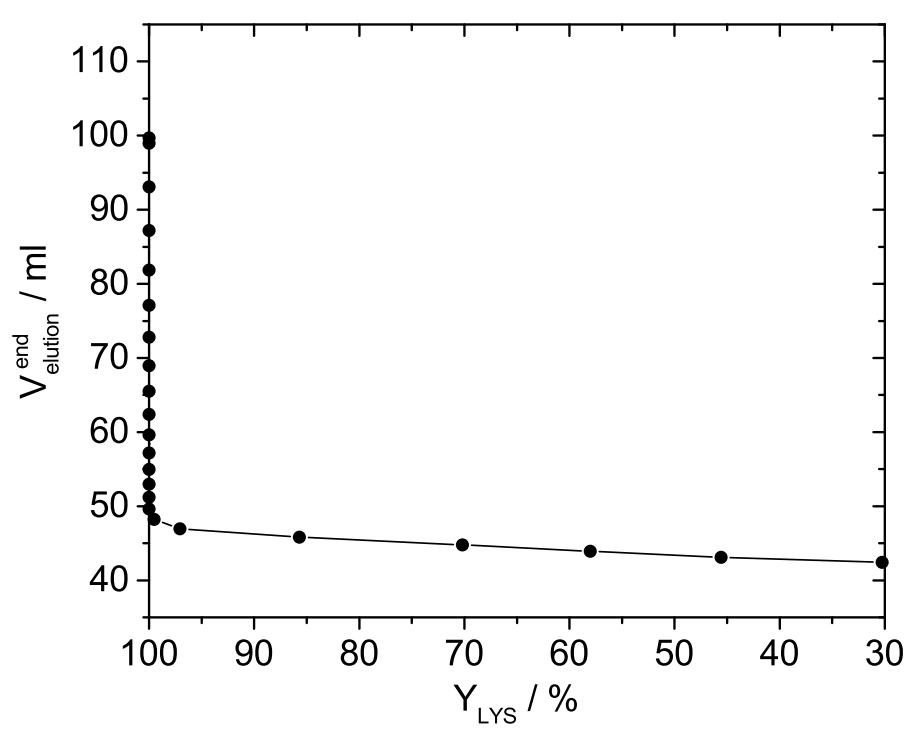

Figure 9: Pareto front showing the elution time and the separation yield of LYS for several isocratic elutions at different values of the overall ionic strength $I$ of the elution buffer. The symbols are the values from the model and the solid line is a spline.

It illustrates the compromise that has to be found between the two competing objectives. The Pareto front of the present separation problem shows the typical knee and has parts in which one objective can be improved at practically no cost regarding the other objective. The optimal operating point is chosen from the region of the knee, which is very sharp for the present problem. E.g., the following 
operating point could be selected: $\mathrm{Y}_{\mathrm{LYS}}=99.5 \%$ and $V_{\text {elution }}^{\text {end }}=48.2 \mathrm{ml}$, which corresponds to using an overall ionic strength of $1.23 \mathrm{M}$.

The contour plot can also be used for a preliminary assessment of the effects of gradient elution. An example is shown in Figure 8 (panel (b)). The linear gradient of the ionic strength is a straight line in the diagram that is defined by two points. The first point is defined by the initial value of the overall ionic strength. In the example it is $2.0 \mathrm{M}$ at $V_{\text {elution }}=0 \mathrm{ml}$. To find the second point, the following is considered. A good separation of BSA and LYS is only achieved above $I \approx 1.2 \mathrm{M}$. The valley between the BSA and LYS peaks at that value of the overall ionic strength is found for $V_{\text {elution }} \approx 13 \mathrm{ml}$. This is chosen as the second point for defining the gradient, see Figure 8 (panel (b)). This simple procedure gives some orientation, but no accurate results can be expected, as the construction is based on an over-simplistically assumption: for each value of the elution volume, the gradient defines a value of the overall ionic strength at the entry of the column. In the simple construction in the contour plot, it is assumed that the value of the overall ionic strength had prevailed in the entire column for the entire elapsed time span. Nevertheless, the gradient that was identified in this simple way has been selected for a test experiment, which is described in the next section.

\subsection{Prediction of gradient elution profiles of BSA and LYS}

Two gradient elutions were studied experimentally, one using the linear gradient identified in the previous chapter (Gradient 1) and one using a less steep gradient (Gradient 2: decreasing the overall ionic strength from $2 \mathrm{M}$ to $1.2 \mathrm{M}$ in $90 \mathrm{ml}$ ). The experimental results are compared to the model predictions in Figure 10. 


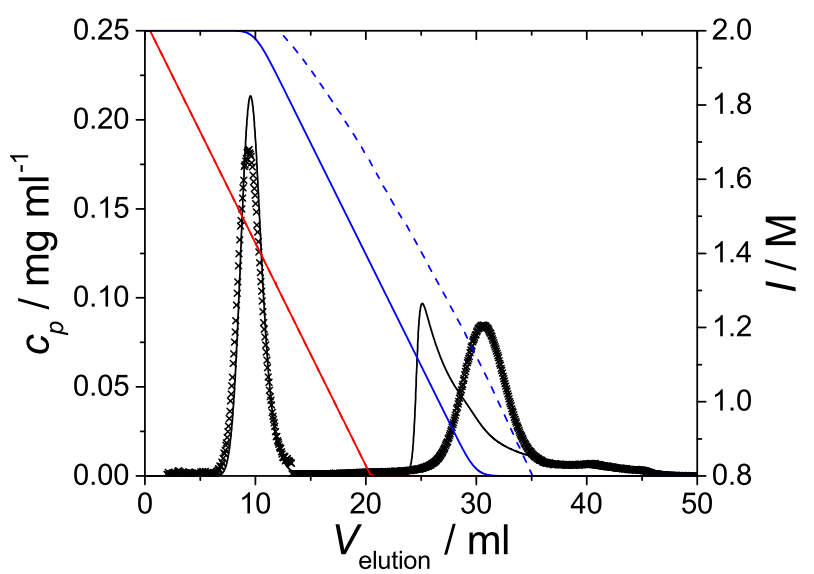

(a)

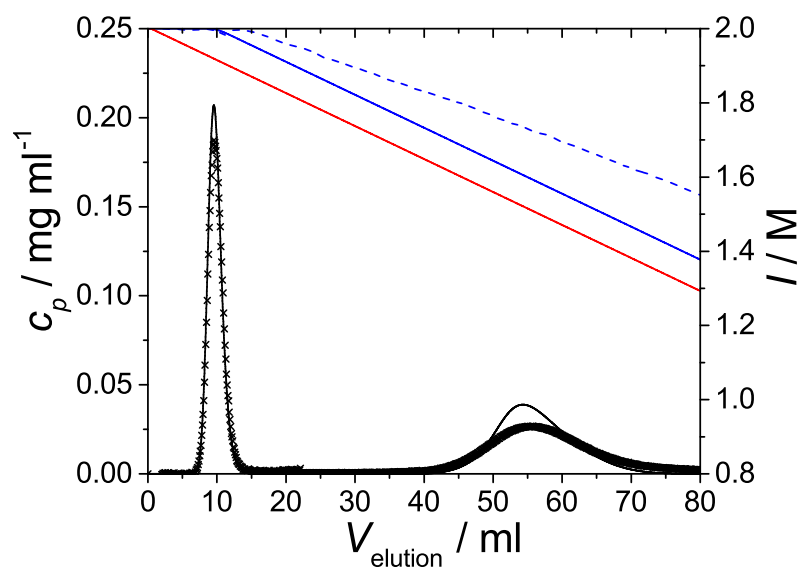

(b)

Figure 10: Gradient elution profiles of protein solutions containing both BSA and LYS at $25^{\circ} \mathrm{C}$ and $\mathrm{pH} 7$ using the adsorbent Toyopearl PPG-600M. $c_{p}^{\text {in }}=1 \mathrm{mg} \mathrm{m}{ }^{-1}$ and $V^{\text {in }}=0.5 \mathrm{ml}$. The elution buffer consists of $1.7 \mathrm{M} \mathrm{NaCl}+0.1 \mathrm{M} \mathrm{Na}_{2} \mathrm{SO}_{4} . I$ is decreased from $2 \mathrm{M}$ to $0.8 \mathrm{M}$ in $20 \mathrm{ml}$ (panel (a)) and from $2 \mathrm{M}$ to $1.2 \mathrm{M}$ in $90 \mathrm{ml}$ (panel (b)). The crosses are experimental values from this work and black lines results from the model. The red and blue dashed lines are the experimental values of the overall ionic strength at the inlet and outlet of the column, respectively. The red and blue continuous lines are the corresponding results from the model. 
For both gradients, a good separation of BSA and LYS is achieved. This is observed in the experiments and also predicted by the model. The model predictions for BSA, which interacts only weakly with the HIC adsorbent, are very good in both cases. The elution profile of LYS is predicted well for Gradient 2, but not for Gradient 1, for which the interaction of LYS with the HIC adsorbent is underestimated. The model predicts also a tailing for this peak, which is not observed in the experiment. These deviations are not unexpected: as mentioned above, the model was trained on data for high salt concentrations and some deviations for experiments with low salt concentrations were already observed in the isocratic experiments with single salts. However, the overall quality of the predictions shown in Figure 10 seems acceptable for a conceptual separation process design. Figure 10 also gives results for the salt concentration at the column inlet and outlet. The values at the inlet are set and therefore identical in the experiment and the simulation. The experimental results for the salt concentration at the column outlet differ from those predicted by the model: the model predicts a faster elution. As the convection velocity for the salt was already set to a low value, this could indicate that the salt interacts with the column and that the interaction should be accounted for in Eq. 15, which would than take the form of Eq. 6.

\section{Conclusion}

In this work, a mathematical model for the prediction of elution profiles of proteins in hydrophobic interaction chromatography (HIC) is presented, with which the influence of salts on the separation of the proteins can be predicted. The adsorption isotherms are predicted using the TAYSI model, which was developed by our group and describes the influence of single and mixed salts on the adsorption 
equilibrium using a Taylor series expansion in the concentrations of single ions. This model of adsorption equilibrium is combined with a lumped model of the adsorption kinetics and a two-dimensional differential mass balance on the column in time and space. The column is assumed to be one-dimensional.

The approach is tested using experimental elution profiles that were measured in the present work with an Äkta purifier. The separation of bovine serum albumin (BSA) and lysozyme (LYS) using the mildly hydrophobic resin Toyopearl PPG$600 \mathrm{M}$ was studied as an example. The salts that were included in the study are: $\mathrm{NH}_{4} \mathrm{Cl}, \mathrm{NaCl},\left(\mathrm{NH}_{4}\right)_{2} \mathrm{SO}_{4}$, and $\mathrm{Na}_{2} \mathrm{SO}_{4}$. Both, single salts and salt mixtures, were used. The adsorption isotherms for the studied systems are known from previous works of our group. Also a version of the TAYSI model that describes these data well is available, and was used in the present work. Hence, all information on the adsorption equilibria is taken from previous work and no adjustment of the adsorption equilibrium model to the elution profiles data was carried out in the present study. However, three parameters of the column model were fitted to elution profiles data of single proteins in buffers with single salts. These parameters are protein-specific but otherwise state-independent. Using this parametrization, the chromatographic separation of BSA and LYS was predicted for isocratic and gradient elutions using single salts and salt mixtures. Overall, good predictions were achieved: the simple model that is proposed here seems sufficient for a conceptual design of HIC separations. The minimum input that is required for each HIC material is one equilibrium isotherm for each protein and each salt that is of interest as well as a single elution profile for each protein that can in principle be measured with any salt. Based on that information, the model can be used for studying the influence of the type of salt, of using mixed salts, of the salt concen- 
tration, of salt gradients, as well as of chromatographic parameters like the flow velocity. No quantitative correctness of the elution profiles can be expected from this simple approach, but the results that were obtained indicate that it is useful for a preliminary identification of promising parameters for the separation that can be used as a starting point for a fine tuning. The choice of parameters usually involves an optimization with conflicting objectives, namely elution volume necessary to complete the elution and separation efficiency. It is shown that the present model enables such Pareto optimizations.

\section{Acknowledgments}

The research project has received funding from the European Communitys Framework Programme for Research and Innovation Horizon 2020 (2014-2020) under grant agreement no.637077. 
[1] K. Mayolo-Deloisa, M. E. Lienqueo, B. Andrews, M. Rito-Palomares, J. A. Asenjo, Hydrophobic interaction chromatography for purification of monoPEGylated RNase A, J. Chromatogr. A 1242 (2012) 11-16.

URL https: //doi.org/10.1016/j.chroma.2012.03.079

[2] D. Josic, L. Breen, J. Clifton, M. S. Gajdosik, D. Gaso-Sokac, M. Rucevic, E. Müller, Separation of proteins from human plasma by sample displacement chromatography in hydrophobic interaction mode, Electrophoresis 33 (12) (2012) 1842-1849.

URL https://doi.org/10.1002/elps.201200006

[3] R. Hahn, Methods for characterization of biochromatography media, J. Sep. Sci. 35 (22) (2012) 3001-3032.

URL https://doi.org/10.1002/jssc.201200770

[4] J. Chen, S. M. Cramer, Protein adsorption isotherm behavior in hydrophobic interaction chromatography, J. Chromatogr. A 1165 (1) (2007) 67-77. URL https: / /doi.org/10.1016/j.chroma.2007.07.038

[5] J. L. Fausnaugh, F. E. Regnier, Solute and mobile phase contributions to retention in hydrophobic interaction chromatography of proteins, J. Chromatogr. A 359 (1986) 131-146.

URL https: //doi.org/10.1016/0021-9673 (86)80068-1

[6] M. E. Lienqueo, A. Mahn, J. C. Salgado, J. A. Asenjo, Current insights on protein behaviour in hydrophobic interaction chromatography, J. Chromatogr. B 849 (1) (2007) 53-68.

URL https : / / doi.org/10.1016/j.jchromb.2006.11.019 
[7] C. Machold, K. Deinhofer, R. Hahn, A. Jungbauer, Hydrophobic interaction chromatography of proteins: I. Comparison of selectivity, J. Chromatogr. A 972 (1) (2002) 3-19.

URL https : / / doi.org/10.1016/s0021-9673(02)01077-4

[8] W. Melander, C. Horváth, Salt effects on hydrophobic interactions in precipitation and chromatography of proteins: An interpretation of the lyotropic series, Arch. Biochem. Biophys. 183 (1) (1977) 200-215.

URL https: / / doi.org/10.1016/0003-9861(77)90434-9

[9] T. W. Perkins, D. S. Mak, T. W. Root, E. N. Lightfoot, Protein retention in hydrophobic interaction chromatography: modeling variation with buffer ionic strength and column hydrophobicity, J. Chromatogr. A 766 (1) (1997) $1-14$.

URL https: / /doi.org/10.1016/S0021-9673(96)00978-8

[10] A. Staby, J. Mollerup, Solute retention of lysozyme in hydrophobic interaction perfusion chromatography, J. Chromatogr. A 734 (1) (1996) 205-212. URL https : / /oi.org/10.1016/0021-9673(95)01161-7

[11] Y.-S. Tsai, F.-Y. Lin, W.-Y. Chen, C.-C. Lin, Isothermal titration microcalorimetric studies of the effect of salt concentrations in the interaction between proteins and hydrophobic adsorbents, Colloids Surf. A 197 (1) (2002) 111118.

URL https : / / doi.org/10.1016/S0927-7757(01)00855-X

[12] F. Xia, D. Nagrath, S. Garde, S. M. Cramer, Evaluation of selectivity changes in HIC systems using a preferential interaction based analysis, Biotechnol. 
Bioeng. 87 (3) (2004) 354-363.

URL https: //doi.org/10.1002/bit.20120

[13] J. M. Mollerup, Applied thermodynamics: A new frontier for biotechnology, Fluid Phase Equilib. 241 (1) (2006) 205-215.

URL https : //doi.org/10.1016/j.fluid.2005.12.037

[14] R. W. Deitcher, J. E. Rome, P. A. Gildea, J. P. O'Connell, E. J. Fernandez, A new thermodynamic model describes the effects of ligand density and type, salt concentration and protein species in hydrophobic interaction chromatography, J. Chromatogr. A 1217 (2) (2010) 199-208.

URL https : / /doi.org/10.1016/j.chroma.2009.07.068

[15] M. R. Mirani, F. Rahimpour, Thermodynamic modelling of hydrophobic interaction chromatography of biomolecules in the presence of salt, J. Chromatogr. A 1422 (2015) 170-177.

URL https://doi.org/10.1016/j.chroma.2015.10.019

[16] E. Müller, J. Vajda, D. Josic, T. Schröder, R. Dabre, T. Frey, Mixed electrolytes in hydrophobic interaction chromatography, J. Sep. Sci. 36 (8) (2013) 1327-1334.

URL https://doi.org/10.1002/jssc.201200704

[17] A. M. Senczuk, R. Klinke, T. Arakawa, G. Vedantham, Y. Yigzaw, Hydrophobic interaction chromatography in dual salt system increases protein binding capacity, Biotechnol. Bioeng. 103 (5) (2009) 930-935.

URL https : / / doi.org/10.1002/bit.22313 
[18] A. Werner, H. Hasse, Experimental study and modeling of the influence of mixed electrolytes on adsorption of macromolecules on a hydrophobic resin, J. Chromatogr. A 1315 (2013) 135-144.

URL https: //doi.org/10.1016/j.chroma.2013.09.071

[19] E. Hackemann, A. Werner, H. Hasse, Influence of mixed electrolytes on the adsorption of lysozyme, PEG, and PEGylated lysozyme on a hydrophobic interaction chromatography resin, Biotechnol. Progr. 33 (4) (2017) 11041115 .

URL https: //doi.org/10.1002/btpr.2474

[20] E. Hackemann, H. Hasse, Influence of mixed electrolytes and pH on adsorption of bovine serum albumin in hydrophobic interaction chromatography, J. Chromatogr. A 1521 (2017) 73-79.

URL https : / /doi.org/10.1016/j.chroma.2017.09.024

[21] Z. El Rassi, L. F. de Ocampo, M. D. Bacolod, Binary and ternary salt gradients in hydrophobic-interaction chromatography of proteins, J. Chromatogr. A 499 (1990) 141-152.

URL https : / /doi.org/10.1016/s0021-9673 (00)96969-3

[22] E. Hackemann, H. Hasse, Mathematical modeling of adsorption isotherms in mixed salt systems in hydrophobic interaction chromatography, Biotechnol. Prog. 34 (5) (2018) 1251-1260.

URL https : / / doi.org/10.1002/btpr.2683

[23] G. Guiochon, A. Felinger, D. G. Shirazi, A. M. Katti, Fundamentals of Preparative and Nonlinear Chromatography, Academic Press, 2006. 
[24] R. Sips, On the Structure of a Catalyst Surface, J. Chem. Phys. 16 (5) (1948) 490-495.

URL https : / /doi.org/10.1063/1.1746922

[25] R. Sips, On the Structure of a Catalyst Surface. II, J. Chem. Phys. 18 (8) (1950) 1024-1026. doi:10.1063/1.1747848.

URL https : / /doi.org/10.1063/1.1747848

[26] A. Creasy, G. Barker, Y. Yao, G. Carta, Systematic interpolation method predicts protein chromatographic elution from batch isotherm data without a detailed mechanistic isotherm model, Biotechnol. J. 10 (9) (2015) 14001411.

URL https : / / doi.org/10.1002/biot.201500089

[27] K. Miyabe, G. Guiochon, Kinetic Study of the Concentration Dependence of the Mass Transfer Rate Coefficient in Anion-Exchange Chromatography of Bovine Serum Albumin, Biotechnol. Prog. 15 (4) (1999) 740-752.

URL https : //doi.org/10.1021/bp990062x

[28] S. M. Pirrung, D. Parruca da Cruz, A. T. Hanke, C. Berends, R. F. W. C. Van Beckhoven, M. H. M. Eppink, M. Ottens, Chromatographic parameter determination for complex biological feedstocks, Biotechnol. Prog. 34 (4) (2018) 1006-1018.

URL https : / / doi.org/10.1002/btpr.2642

[29] P. F. Gomes, J. M. Loureiro, A. E. Rodrigues, Adsorption equilibrium and kinetics of Immunoglobulin $\mathrm{G}$ on a mixed-mode adsorbent in batch and packed 
bed configuration, J. Chromatogr. A 1524 (2017) 143-152.

URL https : / /doi.org/10.1016/j.chroma.2017.10.003

[30] P. F. Gomes, J. M. Loureiro, A. E. Rodrigues, Adsorption of Human Serum Albumin (HSA) on a mixed-mode adsorbent: equilibrium and kinetics, Adsorption 23 (4) (2017) 491-505.

URL https: / /doi.org/10.1007/s10450-017-9861-x 